\title{
Nitrogen Mineralization in a Simulated Rhizosphere as Influenced by Low Molecular Weight Organic Substances
}

\author{
S.A. Begum, M.A. Kader, S. Sleutel and S. De Neve \\ Department of Soil Management, Ghent University \\ Coupure Links 653 \\ 9000 Gent, Belgium
}

Keywords: Low molecular weight organic substances, nitrogen mineralization, rhizosphere, organic acid, carbohydrates, amino acids

\begin{abstract}
The influence of three main groups of low molecular weight organic substances (LMWOS) commonly exuded by plant roots into the rhizosphere such as amino acids (AA), carbohydrates (CHYD) and carboxylic acids (CA) on nitrogen mineralization of a loamy soil from Bangladesh were studied under laboratory condition at $25^{\circ} \mathrm{C}$ for 14 days in a simulated rhizosphere. For this purpose four different treatments (in three replicates) with addition of artificial LMWOS, namely (1) low molecular weight organic acids (a mixture of malic, tartaric, succinic, citric and lactic acid at a C-ratio of 80:9:5:4:2), (2) carbohydrates (glucose), (3) a mixture of amino acids (a mixture of histidine, valine, glycine and alanine at a C-ratio of 43:35:14:9) along with a (4) control were artificially injected in the simulated rhizosphere under saturated conditions at a rate of 103,93 and $10 \mu \mathrm{g} \mathrm{C} \mathrm{g}^{-1}$ soil week $^{-1}$ for low molecular weight organic acids, carbohydrates and amino acids, respectively. $\mathrm{N}$ mineralization was assessed by extracting and measuring $\mathrm{NO}^{-}$and $\mathrm{NH}_{4}^{+}$ concentrations at regular time intervals while microbial biomass $\mathrm{C}\left(\mathrm{OC}_{\mathrm{mic}}\right)$ at the end of the experiment. The $\mathrm{OC}_{\text {mic }}$ was significantly higher in all the amended soils compared with control. The utilization of added OC was highest from AA followed by CHYD and OA. Significant higher N mineralization rate was obtained from AA amended soil whereas OA and CHYD amended soil showed a decrease in N mineralization compared with control soil probably due to $\mathrm{N}$ immobilization. A positive 'priming effect' probably developed due to Low molecular weight organic substances (LMWOS) amendment.
\end{abstract}

\section{INTRODUCTION}

Low molecular weight organic substances (LMWOS) are released into soil by root exudation or by plants and during microbial litter decomposition. Rhizodeposits (i.e. root exudates) consist of over 200 organic compounds, mainly LMWOS such as amino acids (AA), carbohydrates $(\mathrm{CH})$ and carboxylic acids (CA), lipids and phenols (Farrar et al., 2003; Kraffczyk et al., 1984). Among those LMWOS sugars (50-70\% of total exudate), carboxylic acids (20- 30\% of total exudate) and amino acids (10 $20 \%$ of total exudate; Kraffczyk et al. 1984; Jones 1998; Hütsch et al. 2002) are the three main groups of organic substances exuded by roots into the rhizosphere. These LMWOS are involved in various processes in soil including microbial decomposition, sorption, leaching, and uptake by microorganisms and plants (Jones and Edwards, 1998). Many studies have shown that organic acids enhance plant nutrient mobilization in the rhizosphere by the formation of organometallic complexes (e.g. P, $\mathrm{Fe}, \mathrm{Cu}, \mathrm{Mn}$; Hinsinger et al. 2003; Dakora and Phillips 2002). Organic acid release may also change the $\mathrm{pH}$ of the rhizosphere directly or indirectly, which can also increase nutrient availability and affect cell membrane permeability (Jones et al. 
2004). While sugars and proteinaceous amino acids are not directly involved in nutrient mobilization within the rhizosphere they can both act as chemoattractants to certain microorganisms and are involved in supporting microbial growth (Dakora and Phillips 2002).

Kuzyakov (2002) hypothesized that due to their labile nature, the LMWOS components of rhizodeposits are the most important priming agents in the rhizosphere. In comparison to root-free soil, rhizospheric soil receives greater inputs of labile $\mathrm{C}$ and possesses a higher microbial activity (Farrar et al. 2003) which in turn, affects the rate of turnover of soil organic matter and the release of nutrients compared with the bulk soil.

Nitrogen is the most limiting nutrient to plant productivity in terrestrial ecosystems (Vitousek and Horwath, 1991). Nitrate and ammonium are the dominant $\mathrm{N}$ forms available for plants. Thus, mineralization of organic $\mathrm{N}$ is usually regarded as necessary before plant uptake of $\mathrm{N}$ can take place (Haider, 1996). Gross rates of N mineralization in rhizosphere soil were found about 10 times higher than in bulk soil (Herman et al., 2006). Highly soluble LMWOS are rapidly mineralized by soil microorganisms and influence nutrient turnover, particularly $\mathrm{N}$ turnover. Due to multiple factors and their complex interactions in soil, LMWOS transformations in soil are difficult to study (Kuzyakov and Jones, 2006) and the relevance of individual fluxes remains poorly understood. Moreover the majority of research on this matter was focussed on maize and wheat rhizodeposition, while a large knowledge gap for other key food crops, such as rice remains. Therefore, the aim of this study was to investigate the effects of individual group of LMWOS on nitrogen mineralization in a simulated rhizosphere of a paddy soil from Bangladesh.

\section{MATERIALS AND METHODS}

Soil

The soil used in this study was a loamy, mixed non acid Typic Haplaquept situated in Bangladesh (24⒋ $\left.4^{\prime} 32^{\prime \prime} \mathrm{N}, 9^{\circ} 24^{\prime} 19^{\prime \prime} \mathrm{E}\right)$. Soil samples were collected from the top $15 \mathrm{~cm}$ of a medium lowland field under Rice cropping pattern and was sieved ( $<2 \mathrm{~mm}$ ) after air drying. The soil contained $17 \mathrm{~g} \mathrm{~kg}^{-1}$ total organic $\mathrm{C}, 1.85 \mathrm{~g} \mathrm{~kg}^{-1}$ total $\mathrm{N}, 15 \%$ sand, $60 \%$ silt and $25 \%$ clay, and had a $\mathrm{pH}_{\mathrm{kcl}} 5.47$.

\section{Experimental set-up}

A two week incubation experiment was set up consisting of four different treatments with addition of artificial LMWOS, namely (1) low molecular weight organic acids (a mixture of malic, tartaric, succinic, citric and lactic acid at a C-ratio of 80:9:5:4:2), (2) carbohydrates (glucose), (3) amino acids (a mixture of histidine, valine, alanine and glycine at a C-ratio of 43:35:9:14) along with a (4) control. Treatments were applied in three replicates at six sampling dates with artificial LMWOS under saturated condition. Therefore, a total of $72(4 \times 3 \times 6)$ tubes were used for incubation and $100 \mathrm{~g}$ soil was used per tube. In this experiment a novel method was used for the simulation of rhizospheric environment by localized application of the LMWOS and sampling of the artificial rhizosphere. To this end, small perforated plastic straws (diameter $\mathrm{x} \mathrm{mm}$ ) were inserted into the soil columns and the soil in these straws, representing the rhizosphere was sampled separately. After 7 days of pre-incubation at $25^{\circ} \mathrm{C}$ under saturated condition, LMWOS were 
artificially injected with a needle inside the perforated straws at a rate of 103, 93 and $10 \mu \mathrm{g} \mathrm{C} \mathrm{g}^{-1}$ soil week ${ }^{-1}$ from low molecular weight organic acids, carbohydrates and amino acids, respectively, by moving the needle slowly upwards while releasing the exudates. LMWOS were added twice in whole incubation period. Samplings were done at 1, 3, 7, 9, 11 and 14 days after 1st addition of LMWOS. During sampling, 3 tubes per treatment were taken out and soils inside the perforated plastic straws were sampled separately. Only $6 \mathrm{~g}$ of soil was collected from these straws and was extracted with $1 \mathrm{M} \mathrm{KCl}$ (1:5 ratio). The moisture content of the soil inside the straws was considered equal to the moisture content of the bulk soil. The $\mathrm{KCl}$ extracts were analysed for mineral $\mathrm{N}\left(\mathrm{NO}_{3}{ }^{-}\right.$and $\left.\mathrm{NH} 4^{+}\right)$concentration by a continuous flow analyzer (SKALAR instruments).

The $\mathrm{N}$ mineralization rate was calculated using a zero-order kinetic model: $\mathrm{Nt}$ $=\mathrm{N} 0+\mathrm{kt}$, where $\mathrm{t}$ is the time (in days), $\mathrm{Nt}$ is the amount of mineral $\mathrm{N}$ at time $\mathrm{t}, \mathrm{N} 0$ is the initial amount of mineral $\mathrm{N}\left(\mathrm{mg} \mathrm{N} \mathrm{kg}^{-1}\right)$, and $\mathrm{k}$ is the mineralization rate $(\mathrm{mg} \mathrm{N}$ $\mathrm{kg}^{-1}$ day $^{-1}$ ).

\section{Microbial biomass}

The soil microbial biomass $\mathrm{OC}\left(\mathrm{OC}_{\mathrm{mic}}\right)$ was determined at the end of the incubation period by the fumigation-extraction method (Vance et al., 1987). Soil samples were fumigated with ethanol-free $\mathrm{CHCl}_{3}$ for $24 \mathrm{~h}$. After fumigant removal, the soils were extracted by shaking for $1 \mathrm{~h}$ with $0.5 \mathrm{M} \mathrm{K}_{2} \mathrm{SO}_{4}$ and then $\mathrm{K}_{2} \mathrm{SO}_{4}$ extracts before and after fumigation were filtered through paper filters (Whatman 5). The content of organic $\mathrm{C}$ in the extracts (DOC) was measured with a TOC-analyzer (Shimadzu, Japan).

\section{Statistical analysis}

The differences in $\mathrm{N}$ mineralization rates between treatments were determined by one way ANOVA (SPSS 15.0) followed by Duncan's Multiple Range Test (DMRT). Differences at a level of $P<0.05$ were considered significant.

\section{RESULTS AND DISCUSSIONS}

The $\mathrm{N}$ mineralization with LMWOS amendment under waterlogged conditions was represented entirely by the evolution of $\mathrm{NH}_{4}{ }^{+}-\mathrm{N}$ as the evolution of $\mathrm{NO}_{3}{ }^{-}-\mathrm{N}$ was negligible. Soil amendment with LMWOS increased or decreased the net $\mathrm{N}$ mineralization, but mineralisation patterns differed depending on the added organic substances (Figure 1).

There was a significant difference in $\mathrm{N}$ mineralization rate among $\mathrm{OA}$, glucose and AA applied simulated rhizopheres (Figure 2). A significantly higher net $\mathrm{N}$ mineralization rate was measured in the AA amended soil $\left(5.73 \mathrm{mg} \mathrm{N} \mathrm{kg}^{-1} \mathrm{~d}^{-1}\right)$ compared with the control soil $\left(4.23 \mathrm{mg} \mathrm{N} \mathrm{kg}^{-1} \mathrm{~d}^{-1}\right)$. The net $\mathrm{N}$ mineralization rate of the CHYD added soil (4.33 mg N kg-1 $\mathrm{d}^{-1}$ ) was not significantly different from the control and the $\mathrm{N}$ mineralization in the $\mathrm{OA}$ amended soil was significantly higher (3.33 mg N kg $\mathrm{mg}^{-1} \mathrm{~d}^{-1}$ ). There was also a substantial difference in microbial biomass among the treatments (Table 1) with highest $\mathrm{OC}_{\text {mic }}$ in $\mathrm{CHYD}$ amended soil followed by $\mathrm{OA}$ and $\mathrm{AA}$ amended soil. However, the utilization of added $\mathrm{OC}$ by microbes was much higher in AA amended soil $\left(167 \mu \mathrm{g} \mathrm{OC}_{\text {mic }} 100 \mu \mathrm{g}^{-1}\right.$ added OC) compared to CHYD $\left(25 \mu \mathrm{g} \mathrm{OC}_{\text {mic }} 100 \mu \mathrm{g}^{-1}\right.$ added OC) and OA (18 $\mu \mathrm{g} \mathrm{OC}_{\text {mic }} 100 \mu \mathrm{g}^{-1}$ added OC) (Figure 3 ). 
A lower net $\mathrm{N}$ mineralization in the only OC amended soil, particularly in OA amended soil contrasts with the higher microbial biomass in these treatments. A lower apparent $\mathrm{N}$ mineralization in $\mathrm{OA}$ and $\mathrm{CHYD}$ treatments compared to the control might have resulted from microbial $\mathrm{N}$ immobilization. Although we did not directly measure immobilization, increased $\mathrm{OC}_{\text {mic }}$ (by 40-50\%) may have resulted in immobilization of part of the mineralized $N$ (Table 1). Such immobilization is suggested by sudden drops in the soil mineral $\mathrm{N}$ content at days 1 and 8 following application of CHYD. The 14 day time period would likely be too short to observe a potential re-release of this microbial N. Landi et al. (2006) also reported a higher gross $\mathrm{N}$ mineralization and immobilization in rhizosphere soil amended with glucose and oxalic acid. Alternatively an interference of $\mathrm{NH}_{4}$ exchange between the soil solution and fixed $\mathrm{NH}_{4}$ might explain lower net $\mathrm{N}$ mineralization in the CHYD and CA treated soils. Lower redox-potential have been shown to promote fixation of $\mathrm{NH}_{4}$ to clay minerals (Zhang and Scherer, 2000). A rapid decrease in the redox potential occurs following submersion of soils and this decrease would be enlarged by intensive mineralization of added organic materials.

Significantly higher $\mathrm{N}$ mineralization rate observed with application of AA appears logical as the AA contains easily mineralizable N. However, the increase in $\mathrm{N}$ mineralization due to AA amendment was more than three times $\left(33.3 \mathrm{mg} \mathrm{N} \mathrm{kg}^{-1}\right.$ soil $\left.14 \mathrm{~d}^{-1}\right)$ than the added AA-N (9.2 mg N kg${ }^{-1}$ soil $\left.14 \mathrm{~d}^{-1}\right)$. This substantial higher $\mathrm{N}$ mineralization in AA amended soil may be due to a priming effect on microbial SOM degradation. It has been hypothesized that the release of this labile organic substance into the soil will facilitate the mineralization of native soil organic matter (Kuzyakov, 2002). Amino acid also supplies labile $\mathrm{C}$ to the soil in addition to labile $\mathrm{N}$ which may enhance microbial activities in soil. The highest microbial utilization of added organic carbon was in the AA amended soil (Figure 3) and this supports this hypothesis. Microbial intake of more than the added OC (from native SOM) in AA amended soil derives from enhanced native SOM mineralization in this treatment. $\mathrm{N}$ transformations in the rhizosphere soils are related to $\mathrm{C}$ dynamics and release of the available $\mathrm{C}$ from roots. For example, in the presence of maize roots, $67 \%$ more soil mineral $\mathrm{N}$ was immobilized into organic $\mathrm{N}$ than without plants, despite a higher competition by plants for mineral N (Qian et al, 1997). Here, the experiment shows a positive effect of $\mathrm{C}$ addition on $\mathrm{N}$ mineralization.

However, it is difficult to distinguish the influence of root exudation on $\mathrm{N}$ mineralization in field condition over other processes operating concurrently in the rhizosphere (e.g. drying of the soil around roots, physical disturbance of the soil, extra-radical mycorrhizal hyphal growth, increased mesofaunal activity (Kuzyakov, 2002). Here we attempted to simulate the rhizosphere to look at the influence of LMWOS on $\mathrm{N}$ mineralization in isolation. Our results showed that the addition of three common LMWOS (a mixture of LMWOA, glucose and a mixture of AA) to a simulated rhizosphere had small, substrate specific effect on $\mathrm{N}$ mineralization.

\section{CONCLUSIONS}

The addition of representative amounts of three common LMWOS (organic acid, glucose and amino acid) into a simulated rhizosphere showed that locally high concentrations of (artificial) LMWOS stimulate microbial biomass and SOM decomposition. This enhanced mineralization was not always concomitant with 
enhanced $\mathrm{N}$ mineralization. We assessed net $\mathrm{N}$ mineralization through the follow-up of mineral $\mathrm{N}$ content in soil, which, however, excludes mineralized $\mathrm{N}$ that has been readily immobilized into microbial biomass. Such microbial immobilization was indicated from drops in mineral $\mathrm{N}$ content and increased microbial OC. Alterations to $\mathrm{N}$ mineralization by input of $\mathrm{OA}$, glucose or AA as observed in these simulated rhizospheres may not be similar to real rhizosphere as all the rhizodeposits and actively growing roots work together in a complex manner.

\section{ACKNOWLEDGEMENT}

S.A. Begum and M.A. Kader wish to acknowledge the Flemish InterUniversity Council (VLIR) for providing a PhD grant to carry out this research. S. Sleutel is working as a post-doctoral researcher for the Flemish Research Foundation (FWO).

\section{Literature Cited}

Dakora, F.D. and Phillips, D.A. 2002. Root exudates as mediators of mineral acquisition in low-nutrient environments. Plant Soil 245:35-47.

Farrar, J., Hawes, M., Jones, D., and Lindow, S. 2003. How roots control the flux of carbon to the rhizosphere. Ecology 84:827-837.

Haider, K. 1996. Biochemie des Bodens. Ferdinand Enke Verlag, Stuttgart, 174 pp.

Herman, D.J., Johnson, K.K., Jaeger III, C.H., Schwartz, E. and Firestone, M.K. 2006. Root Influence on Nitrogen Mineralization and Nitrification in Avena barbata Rhizosphere Soil. Soil Sci. Soc. Am. J. 70:1504-1511.

Hinsinger, P., Plassard, C., Jaillard, B. and Tang, C.X. 2003. Origins of root-mediated $\mathrm{pH}$ Changes in the rhizosphere and their responses to environmental constraints: a review. Plant Soil 248:43-59.

Hütsch, B.W., Augustin, J. and Merbach, W. 2002. Plant rhizodeposition - an important source for carbon turnover in soils. J. Plant Nutr. Soil Sci. 165:397-408.

Jones, D.L. and Edwards, A.C. 1998. Influence of sorption on the biological utilization of two simple carbon substrates. Soil Biol. Biochem. 30:1895-1902.

Jones, D.L. 1998. Organic acids in the rhizosphere - a critical review. Plant Soil 205:25-44.

Jones, D.L., Hodge, A. and Kuzyakov, Y. 2004. Plant and mycorrhizal regulation of rhizodeposition. New Phytol. 163:459-480.

Kraffczyk, I., Trolldenier, G. and Beringer, H. 1984. Soluble root exudates of maize: influence of potassium supply and rhizosphere microorganisms. Soil Biol. Biochem. 16:315-322.

Kuzyakov, Y. 2002. Review: factors affecting rhizosphere priming effects. J. Plant Nutr. Soil Sci. 165:382-396.

Kuzyakov, Y. and Jones, D.L. 2006. Glucose uptake by maize roots and its transformation in the rhizosphere. Soil Biol. Biochem. 38: 851-860.

Landi, L., Valori, F., Ascher, J., Renella, G., Falchini, L. and Nannipieri, P. 2006. Root exudate effects on the bacterial communities, $\mathrm{CO}_{2}$ evolution, nitrogen transformations and ATP content of rhizosphere and bulk soils. Soil Biol. Biochem. 38: 509-516.

Qian, J.H., Doran, J.W. and Walters, D.T. 1997. Maize plant contribuctions to root zone available carbon and microbial transformations of nitrogen. Soil Biol. Biochem. 29: 1451-1462.

Vance, E.D., Brookes, P.C. and Jenkinson, D.S. 1987. An extraction method for measuring soil microbial biomass C. Soil Biol. Biochem.19: 703-707. 
Vitousek, P. M. and Howarth, R. W. 1991. Nitrogen limitation on land and in the sea: How can it occur? Biogeochem. 13:78-116.

Zhang, Y. and Scherer, H. W. 2000. Mechanisms of fixation and release of ammonium in paddy soils after flooding II. Effect of transformation of nitrogen forms on ammonium fixation. Biol. Fertil. Soils 31:517-521.

\section{Tables}

Table 1 Microbial Biomass organic carbon $\left(\mathrm{OC}_{\text {mic }}\right)$ as influenced by artificial LMWOS (average \pm standard deviation)

\begin{tabular}{lc}
\hline Treatments & $\mathbf{O C}_{\mathbf{m i c}}\left(\boldsymbol{\mu g} \mathbf{C ~ g}^{-1}\right.$ soil $)$ \\
\hline Control & $92.59 \pm 41.9$ \\
Organic acid & $130.37 \pm 25.2$ \\
Carbohydrate & $139.98 \pm 33.1$ \\
Amino acid & $126.09 \pm 30.3$ \\
\hline
\end{tabular}

\section{$\underline{\text { Figures }}$}

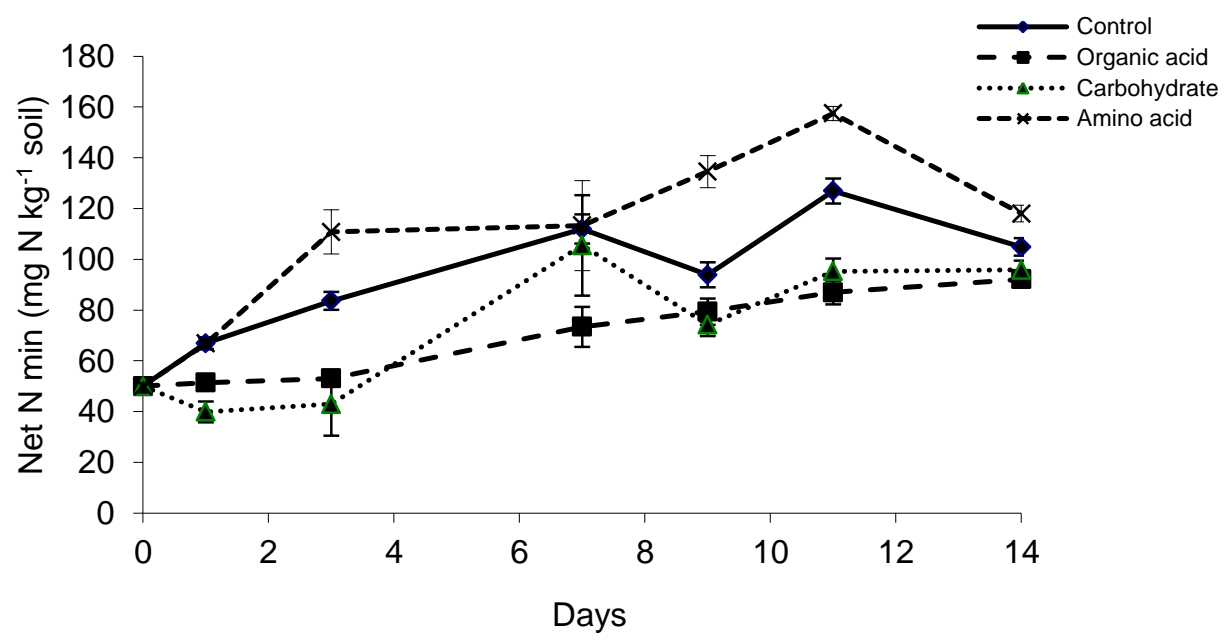

Figure 1. Evolution of mineralized $\mathrm{N}$ in the soil with localized application of artificial LMWOS under saturated condition. The error bars are the standard deviation of the means $(n=3)$. 


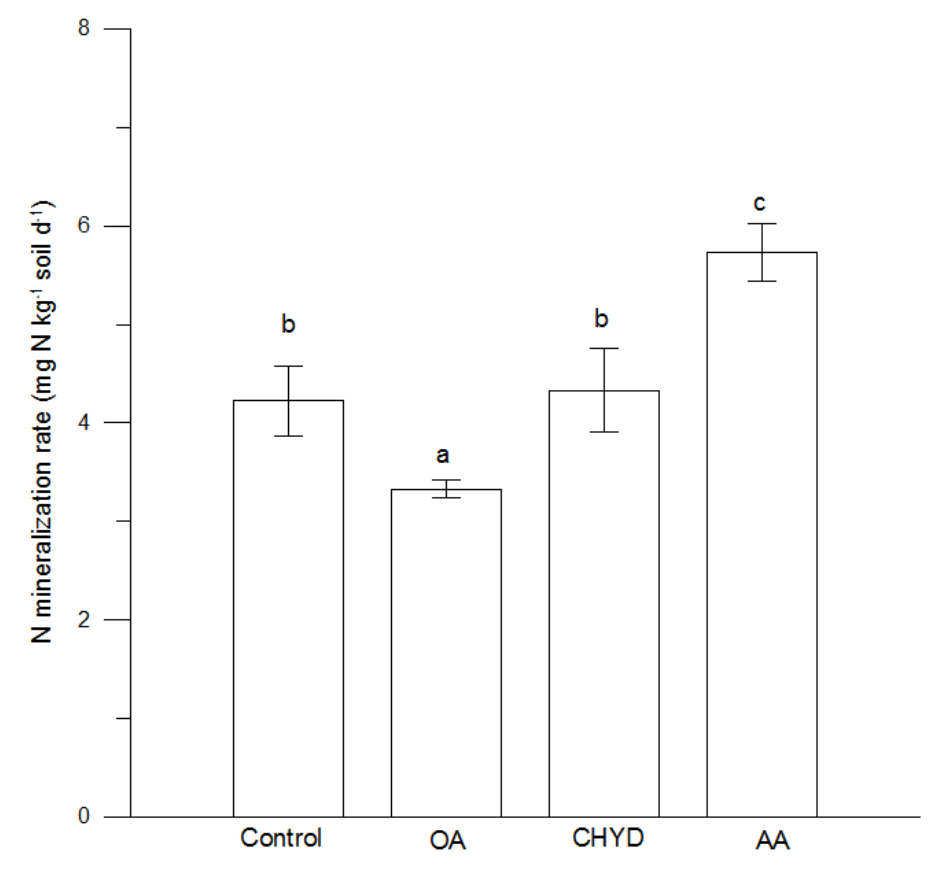

Figure 2. Nitrogen mineralization rate from control soil and organic acids (OA), carbohydrate (CHYD as glucose) and amino acids (AA) treated soils. (Bars represent means per treatment with standard errors in vertical error bars. Means with $(n=3)$ different letters are significantly different at $P<0.05$ ).

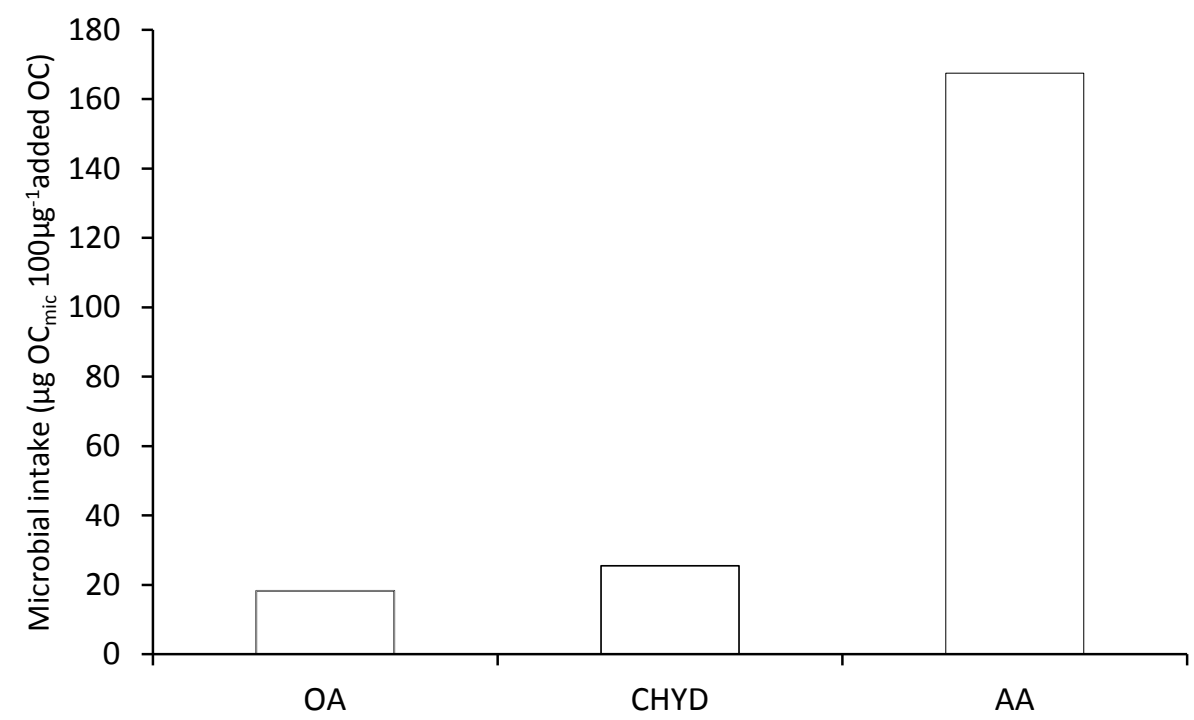

Figure 3 Microbial intake of added organic carbon from different LMWOS amended to the soil under saturated condition 